6. Gusmão S, Silveira RL, Cabral Filho G, Arantes A. Relações do osso parietal com a face súpero-lateral do cérebro: aplicações na localização das lesões cerebrais. J Bras Neurocirurg 2000;11:53-56.

7. Gusmão S, SilveiraRL, Cabral G, ArantesA. Topografia craniencefálica: aplicações neurocirúrgicas. Arq Bras Neurocirug 1998;17:59-71.

8. Ribas CG. Estudo das relações topográficas das suturas lambdóide, occipitomastóidea e parietomastóidea com os seios transverso e sigmóide, edetrepanações da região. Tese (Doutorado), Faculdade de Medicina, Universidade de São Paulo. São Paulo, 1991

Guilherme Carvalhal Ribas

Doutor em Medicina (Neurologia) pela Universidade de São Paulo (USP),

Neurocirurgião Coordenador do Setor de Neuroanatomia Aplicada da Disciplina de Topografia Estrutural Humana do Departamento de Cirurgia da Faculdade de Medicina da USP.

Resposta do Autor - Pela presente respondemos aos comentários do Prof. Guilherme Carvalhal Ribas referentes ao artigo "Pontos referencias nos acessos cranianos". O comentário fundamental prende-se ao fato de alguns dos pontos descritos não estarem justificados por referências bibliográficas. $\mathrm{Na}$ Introdução do artigo anunciamos que "O objetivo do presente trabalho é sistematizar os pontos referenciais nos acessos cranianos". Assim, nosso objetivo foi de sistematizar, ordenar pontos referenciais usados na prática diária do neurocirurgião durante as craniotomias. Não se trata, portanto, de trabalho morfométrico nem de revisão da literatura. Entretanto, para sistematizar os referidos pontos, baseamos em nossos trabalhos morfométricos realizados em cadáveres e publicados nos Arquivos de Neuropsiquiatria, em trabalho da literatura e em nossa prática neurocirúrgica.

Os nove pontos (dentre os 22 descritos) e não justificados por referência são pontos que usamos diariamente em nossa prática neurocirúrgica, da mesma forma que os demais neurocirurgiões. Estes pontos são de conhecimento e uso geral, representados rotineiramente em ilustrações de livros texto, mas sobre os quais não foram publicados qualquer estudo morfométrico. Portanto, não poderíamos validá-los por meio de referência bibliográfica específica. Concordamos com o comentarista que teria sido mais apropriado e preciso informar que estes pontos são de conhecimento clássico e de uso rotineiro na prática neurocirúrgica apesar de não terem sido submetidos a estudo morfométrico.

O Professor Carvalhal Ribas comenta especialmente os pontos descritos no trabalho como "Ponto de junção dos sulcos frontal superior e pré-central" e "Ponto intraparietal". A identificação do "Ponto de junção dos sulcos frontal superior e pré-central" é obtida a partir das medidas, por nós realizadas, da distância entre a sutura coronária e o sulco pré-central e entre o bregma e a interseção da sutura coronária com o sulco frontal superior (Gusmão et al. Relações da sutura coronária com os sulcos da face súpero-lateral do lobo frontal: aplicações neurocirúrgicas. Arq Neuropsiquiatr 59: 570 - 576, 2001). Quanto ao "Ponto Intraparietal", é usado de forma empírica em nosso serviço para abordagem do átrio ventricular, embora (como em outros pontos) não exista estudo morfométrico sobre o mesmo.

Os pontos apontados pelo Professor Carvalhal Ribas e usados de forma empírica na prática neurocirúrgica carecem ainda de estudo morfométrico preciso. Os trabalhos projetados pelo referido Professor deverão cumprir tal objetivo, como o fizeram em relação aos pontos de acesso à fossa posterior, estudados em sua tese de doutorado, e cujo trabalho constitui referência básica em topografia cranioencefálica e nos inspiraram a estudar o assunto.

Sebastião Gusmão

\title{
COMPUCAÇÃO DE DERIVAÇÃO VENTRÍCULO-PERITONEAL: HÉRNIA INGUINAL COM MIGRAÇÃO DO CATETER PARA O SACO ESCROTAL
}

Senhor Editor - O relato de caso denominado “Complicação de derivação ventrículo-peritoneal: hérnia inguinal com migração do cateter para o saco escrotal", de osé Gilberto deBrito Henriques, Andréa Silva Pinho e Geraldo Pianetti, publicado no volume 61, número 2-B, de junho de 2003, nas páginas 486 a 489, merece algumas considerações:

1. A hidrocele e a hérnia inguinal são complicações comuns associadas à derivação ventrículo- peritoneal (DVP) e a fisiopatologia foi muito bem discutida no presente artigo;

2. O diferencial deste relato foi a constatação da migração do cateter distal para dentro da bolsa escrotal;

3. Assim, o esperado é que os autores discutissem a fisiopatologia da ocorrência do evento "migração do cateter para o saco escrotal";

4. Mas isto não ocorreu. Toda a discussão versou sobre as causas das hidroceles e da hérnia inguinal. 
5. No caso descrito, a resposta da provável razão da migração do cateter distal da DVP para dentro do saco escrotal está na figura 3 , do próprio artigo, que apresenta os raios- $X$ simples de abdome com o cateter anormalmente e desnecessariamente muito longo.

6. A comprovação de que o tamanho do cateter está exagerado pode ser visualizado na figura 4, do próprio artigo, onde se percebe o cateter com grande número de voltas.

7. É importante que este relato de caso seja rediscutido no seu aspecto mais essencial que é a migração do cateter. É preciso que, ao se realizar uma DVP, o neurocirurgião esteja consciente de que o comprimento muito longo do cateter distal proporcionará possibilidades maiores de complicações, especialmente as relacionadas com migrações para trato gastrointestinal, parede abdominal, bexiga, mediastino, vagina, tórax, entre outros ${ }^{1-5}$.

A justificativa para se optar por um cateter distal longo é de que, na maioria das vezes, a DVP é utilizada em crianças muito pequenas, com meses de vida. Com o crescimento normal da criança, o cateter com dimensões adequadas para o bebê, tornarse-ia curto, sendo necessária sua substituição por um mais longo. Assim, para evitar uma revisão do sistema de DVP aos três ou quatro anos de idade, a opção pelo cateter longo traria benefícios. Entretanto, os movimentos peristálticos do trato intestinal e o processo vaginal patente (de ocorrência em cerca de $80 \%$ dos lactentes ${ }^{1}$, determinam que a opção por cateter muito longo, facilita o desenvolvimento de complicações por migração.

\section{REFERÊNCIAS}

1. Oktem IS, A kdemir $\mathrm{H}, \mathrm{Koç} \mathrm{C}$, et al. Migration of abdominal catheter of ventriculoperitoneal shunt into the scrotum. Acta Neurochir (Wien) 1998;140:167-170.

2. Pianetti G Filho, Cabral G, Fonseca LF, Val JAC Filho. Perfuração vaginal como complicação de derivação ventrículo-peritoneal. Arq Neuropsiquiatr 1991;49:362-364.

3. Calvário JS, Paglioli E Neto. Hydrocele following placement of a ventriculoperitoneal shunt: case report. Arq Neurpsiquiatr 1990;48:113-115.

4. Tuli S, Drake J, Lawless J, Wigg M, Lamberti-Pasculli M. Risk factors for repeated cerebrospinal shunt failures in pediatric patients with hydrocephalus. J Neurosurg 2000;92:31-38.

5. Tuli S, O'Hayon B, Drake J, Clarke M, Kestle J. Change in ventricular size and effect of ventricular catheter placement in pediatric patients with shunted hydrocephalus. Neurosurgery 1999;45:1329-1333.

Vicente José Assencio-Ferreira Doutor em Medicina (Neurologia) pela Universidade de São Paulo (USP), Professor Assistente Doutor da Universidade de Taubaté (UNITAU)
Resposta do Autor - Atendendo à sua solicitação de resposta à carta do Professor AssencioFerreira, ponderamos os seguintes pontos.

1. Independente de qualquer outro fator, a patência do processo vaginal - com ou sem a ocorrência de hérnia inguinal ou hidrocele - é condição sine qua non para a ocorrência da migração do cateter abdominal da DVP para a bolsa escrotal.

2. Alguns outros fatores já foram associados à migração do cateter para diversos locais dentro ou através da cavidade abdominal porém faltam-lhes ainda comprovação prática e científica.

3. O tamanho do cateter abdominal é um dos fatores relacionados por al guns autores (citados pelo Professor Assencio-Ferreira e em nossa revisão bibliográfica) que já foram relacionados à migração do cateter abdominal. Entretanto, em nenhum trabaIho revisto na literatura vigente há comprovação científica desta relação de causa-efeito. O que ocorre é apenas o levantamento de uma hipótese.

4. Em relação ao comentário do Professor sobre a maior possibilidade de complicações com o "comprimento muito longo do cateter distal" pensamos que independendo da opção por um cateter "curto" ou "longo" é pouco provável que em um recémnascido ou em um lactente escolha-se um comprimento mínimo que não seja possível atingir a bolsa escrotal do paciente. Acrescentando a este, o fato de que aproximadamente $80 \%$ dos lactentes possuem pelo menos um processo vaginal patente, a incidência de migração do cateter abdominal para a bolsa escrotal é muito pequena para ser associada a seu comprimento.

5. Por isso, o comprimento do cateter ainda varia coma escolha pessoal do cinurgião, pesando-lheo bom senso e a experiência.

O comprimento do cateter distal da DVP não foi comprovado como causa de sua migração ou perfuração de vísceras.

Agradecemos a apreciação do Professor AssencioFerreira e colocamo-nos à disposição. 